\title{
Vasoactive Intestinal Peptide for Diagnosing Exacerbation in Chronic Obstructive Pulmonary Disease
}

\author{
Jyotshna Mandal ${ }^{a, b}$ Michael Rotha, ${ }^{a}$ Luigi Costa ${ }^{b}$ Lucas Boeck $^{a}$ \\ Janko Rakic ${ }^{\mathrm{a}}$ Andreas Scherr $^{\mathrm{a}}$ Michael Tamm $^{\mathrm{a}}$ Daiana Stolz ${ }^{\mathrm{a}}$ \\ ${ }^{a}$ Clinic of Pulmonary Medicine and Respiratory Cell Research, University Hospital Basel, and b Pulmonary Cell \\ Research Laboratory, Department of Biomedicine, University of Basel, Basel, Switzerland
}

For editorial comment see p. 353

\section{Key Words \\ Chronic obstructive pulmonary disease - Acute exacerbation - Serum vasoactive intestinal peptide . \\ Diagnostic biomarker}

\begin{abstract}
Background: Vasoactive intestinal peptide (VIP) is the most abundant neuropeptide in the lung. VIP has been linked to pulmonary arterial hypertension and hypoxia. Objectives: We aimed to assess circulating VIP levels at exacerbation and at stable chronic obstructive pulmonary disease (COPD) and to evaluate the diagnostic performance in a well-characterized cohort of COPD patients. Methods: The nested cohort study included patients with Global Initiative for Chronic Obstructive Lung Disease stage II-IV. Patients were examined at stable state and at acute exacerbation of COPD (AE-COPD), and dedicated serum was collected at both conditions. Serum VIP levels were determined by enzyme-linked immunosorbent assay. Diagnostic accuracy was analyzed by receiver operating characteristic curve and area under the curve (AUC). Results: Patients with acute exacerbation $(n=120)$ and stable COPD $(n=163)$ had similar characteristics at baseline. Serum VIP levels did not correlate with oxygen saturation at rest $(p=0.722)$ or at exercise $(p=0.168)$. Serum VIP
\end{abstract}

(c) 2015 S. Karger AG, Basel

0025-7931/15/0905-0357\$39.50/0 levels were significantly higher at AE-COPD $(130.25 \mathrm{pg} / \mathrm{ml}$, 95\% Cl 112.19-151.83) as compared to stable COPD (40.07 $\mathrm{pg} / \mathrm{ml}, 95 \% \mathrm{Cl} 37.13-43.96, \mathrm{p}<0.001)$. The association of increased serum VIP with AE-COPD remained significant after propensity score matching $(p<0.001)$. Analysis of the Youden index indicated the optimal serum VIP cutoff value as $56.6 \mathrm{pg} / \mathrm{ml}$. The probability of AE-COPD was very low if serum VIP was $\leq 35 \mathrm{pg} / \mathrm{ml}$ (sensitivity $>90 \%$ ) and very high if serum VIP was $\geq 88 \mathrm{pg} / \mathrm{ml}$ (specificity $>90 \%$ ). Serum VIP levels presented a robust performance to diagnose AE-COPD (AUC 0.849, 95\% Cl 0.779-0.899). Conclusions: Increased serum VIP levels are associated with AE-COPD.

(c) 2015 S. Karger AG, Basel

\section{Introduction}

Chronic obstructive pulmonary disease (COPD) is a major global health problem [1] and is the fourth leading cause of death in the world, claiming 3 million annual deaths worldwide $[2,3]$. Exacerbations are the most frequent cause of hospitalization for COPD patients [4]. They are commonly defined as 'an event in the natural course of the disease characterized by a baseline change in the patient's dyspnea, cough, and/or sputum that is be-

\section{KARGER 125}

E-Mail karger@karger.com www.karger.com/res
Prof. Daiana Stolz, MD, MPH, FCCP

Clinic of Pulmonary Medicine and Respiratory Cell Research

University Hospital Basel

Petersgraben 4, CH-4031 Basel (Switzerland)

E-Mail daiana.stolz@usb.ch 
yond the normal day-to-day variations, is acute in onset, and may warrant a change in the regular medication in a patient with underlying COPD' [5]. Today, there is no established gold standard that reliably allows diagnosis of exacerbation $[6,7]$.

Although clear clinical criteria have been defined for COPD exacerbation, its initial diagnosis, especially in older, often multi-morbid patients in a busy general practitioner's office or emergency department tends to be challenging. The main reason is that, with the lack of a confirmatory test for the clinical impression, the diagnosis of COPD exacerbation usually requires the exclusion of alternative diagnoses such as congestive heart failure, pneumonia, bronchial cancer and pulmonary embolism, all commonly found in elderly patients with a history of smoking. This process is not only associated with considerable financial and personal healthcare resources but also delays the timely treatment of exacerbation [8-10]. The lack of a widely accepted, standard definition of exacerbation also hampers the comparability of different studies, thus decreasing the external generalizability of COPD research $[4,11]$. Thus, practically, exacerbations are difficult to diagnose and therefore it is a worthwhile task to explore potential biomarkers that can be appointed for clinical use [12]. Although some proteins have been suggested as potential markers of COPD exacerbation, up to now there is no single factor that can decisively identify it $[13,14]$.

The most abundant neuropeptide in the lung is the vasoactive intestinal peptide (VIP), which is a potent muscle relaxant and has therefore been suggested in the therapy of chronic inflammatory lung diseases, including COPD $[15,16]$. In experimental conditions, VIP has a positive inotropic and chronotropic effect. It relaxes pulmonary and coronary artery smooth muscles and in addition has shown anti-inflammatory effects in animal models [1619]. In COPD rat models, VIP reduced cigarette smokeinduced damage of alveolar cells and apoptosis [20,21]. In smoking COPD patients, increased expression of VIP was reported in the patients' epithelium, while it was downregulated in their airway smooth muscle cell layer as compared to smokers without COPD [22]. A similar increase in VIP was reported in arterial serum samples obtained from patients with COPD and pulmonary arterial hypertension $(\mathrm{PAH})$ [23].

In human bronchial epithelial cells VIP supported wound healing through the cAMP response elementbinding protein (CREB) [24]. Such beneficial effects of VIP on bronchial and alveolar epithelial cells were supported by animal models, where VIP protected against oxidative stress via a second transcription factor, the signal transducers and activators of transcription 3 (STAT3) [25]. Furthermore, application of VIP prevented hyperoxia-induced pathologic lung function and tissue structural changes in rats [26]. Together these results suggest that VIP is regulated and functions in a cell type-specific manner, with a beneficial effect on the regeneration and function of bronchial epithelium. Thus, circulating VIP levels may indicate active inflammation and wound repair in the bronchus and may be useful as an early biomarker of exacerbation in COPD. Recently, attention has been directed towards the therapeutic potential of VIP for the treatment of COPD, as it acts as a neurotransmitter and has anti-inflammatory properties [27].

In this study we investigated serum VIP levels in dedicated samples at AE-COPD and stable state in a wellcharacterized cohort of COPD patients. The accuracy of serum VIP for the diagnosis of exacerbation in COPD was also evaluated.

\section{Subjects and Methods}

\section{Study Design and Patients}

The 'Predicting Outcome Using Systemic Markers in Severe Exacerbations of Chronic Obstructive Pulmonary Disease' (PROMISE-COPD) was a multicenter study, from November 2008 to October 2011, done to evaluate the potential variables associated with poor outcomes in moderate to very severe COPD patients. COPD was defined as post-bronchodilator $\mathrm{FEV}_{1} / \mathrm{FVC}$ $<70 \%$ and $\mathrm{FEV}_{1}<80 \%$ predicted, i.e. Global Initiative for Chronic Obstructive Lung Disease (GOLD) grade II-IV airway obstruction [28].

The study was designed to be inclusive, exploratory and hypothesis-generating. It was specifically drafted to identify predictors of outcome using systemic markers in COPD. In this analysis, a nested, predefined cohort of 241 patients (at stable state and followed up longitudinally) from Basel, Switzerland was included. It was performed according to the PRoBE (prospective specimen collection, retrospective blinded evaluation) standards [29]. The expected follow-up period was 5 years. All enrolled patients had an initial baseline examination at stable state and were followed up for at least 2 years in scheduled half-yearly visits. Blood samples were collected at both stable state and at exacerbation for the purpose of this analysis. When necessary, patients made outpatient visits or were hospitalized for treatment of AE-COPD, and follow-up visits were performed 4 weeks after the onset of exacerbation. The inclusion criteria were: (1) at baseline: clinically stable, moderate to very severe COPD (stages II-IV, according to the GOLD classification) [1] based on anamnesis, physical examination and spirometry $\geq 4$ weeks after the latest exacerbation; (2) age $\geq 40$ years; (3) smoking history $\geq 10$ pack-years. The exclusion criteria were: (1) main respiratory disorder such as asthma, bronchiectasis or pulmonary fibrosis; (2) other fatal disease; (3) immunosuppression, including AIDS, organ transplantation or current chronic 
steroids (>20 mg prednisolone per day); (4) neuromuscular or musculoskeletal disorder preventing walking.

Throughout the study period, patients were treated as clinically warranted, without restriction. They were monitored for recurrent moderate (requiring treatment with systematic corticosteroids, antibiotics or both) and severe AE-COPD (requiring hospitalization or a visit to the emergency department).

The PROMISE-COPD, an investigator-initiated and -driven study, complying with the Helsinki Declaration and Good Clinical Practice Guidelines, was approved by the participating centers' ethics committees (EKBB 295/07) and was registered at www.controlled-trials.com (identifier ISRCTN99586989). All patients provided prior written consent for the study assessments.

\section{Baseline and Scheduled Visit Assessments}

For all patients, we performed a physical examination, registered vital signs and obtained a detailed medical history, which included their demography, smoking status, disease duration, current treatment as well as number and severity of exacerbations in the previous year. From the data the age-adjusted Charlson Comorbidity Index score was calculated. We also obtained plasma samples for measurement of biomarkers and spontaneous sputum samples for quantitative bacterial culture. Physical examinations, spirometry and 6-minute walking tests were performed by qualified personnel according to the guidelines of the American Thoracic Society [30]. Each patient completed the Modified Medical Research Council (MMRC) scale, the St. George's Respiratory Questionnaire, COPD version and the Short Form 36 health-related, quality of life questionnaire. All examinations took place at each scheduled visit (semi-annually), except for the 6-minute walking tests.

Presence of PAH was defined as systolic pulmonary pressure $>35 \mathrm{~mm} \mathrm{Hg}$ within 6 months of baseline and determined by echocardiography.

\section{Outcome Assessment}

At the 2-year follow-up, the vital status of each patient was confirmed and, if required, by relatives, family physicians, medical insurance companies, by checking medical records, hospital databases or public registries. These methods were also used to determine the dates and causes of death, if any. Death dates that were undeterminable were imputed to the halfway point between the last study visit and the date when the investigator learned about the death.

\section{Unscheduled Visits during Exacerbation}

Exacerbation was defined as an acute change from baseline in one or more of dyspnea, cough and sputum, beyond normal dayto-day variation and possibly warranting change in medication. Visits derived from exacerbation were classified as unscheduled visits. Severe exacerbation was defined as the patients having to be admitted to the hospital for treatment [1]. Spontaneously expectorated sputum samples were obtained and examined using standard techniques [31]. Sputum microbiology was performed and good sputum quality was defined as $<25$ epithelial cells in $100 \times$ augmentation. Patients were asked to report to or call the study center on worsening of respiratory symptoms. Chest radiography and electrocardiography were performed at the discretion of the attending physician to exclude other respiratory and cardiac pathologies. $71.6 \%(n=86)$ of the patients had either a chest X-ray or CT scan performed. Electrocardiography was obtained in $13.3 \%(n=16)$ of the patients.

VIP for Diagnosing Exacerbation in COPD
AE-COPD patients were categorized as type 1 (severe with dyspnea, sputum volume and sputum purulence), type 2 (moderate with any two of the above three main symptoms) and type 3 (mild with any one of the three main symptoms) based on Anthonisen's classification of COPD exacerbation [32].

\section{VIP Enzyme-Linked Immunosorbent Assay}

Blood samples for VIP measurement were collected on the scheduled (stable state of the disease) and unscheduled visits (AECOPD) of each patient into Vacutainer tubes through an indwelling venous catheter. Serum was collected after centrifugation $\left(3,000 \mathrm{~g}, 10-15 \mathrm{~min}, 4^{\circ} \mathrm{C}\right)$ and was immediately fast-frozen at $-80^{\circ} \mathrm{C}$ for analysis. In addition, serum samples were drawn at the same visit and processed routinely.

VIP enzyme-linked immunosorbent assay (VIP-ELISA) was performed with fast-frozen samples $(n=241)$ and routinely processed serum samples $(n=20)$ according to the manufacturer's instructions, with a detection range of $15.6-1,000 \mathrm{pg} / \mathrm{ml}$ and $<3.9 \mathrm{pg} /$ $\mathrm{ml}$ sensitivity (Cusabio Biotech Co. Ltd., China). VIP-ELISA was also performed in serum samples obtained from healthy blood donors $(\mathrm{n}=30)$ and used as the reference value of serum VIP ranging from 20 to $22 \mathrm{pg} / \mathrm{ml}$. All serum samples were assayed in duplicate, in a single run by personnel unaware of the patients' clinical data.

\section{Statistics}

Continuous variables are expressed as mean \pm SD or median (interquartile range: 25 th to 75 th percentile) and discrete variables as percentage. Baseline characteristics were compared between patients with stable COPD and AE-COPD by Mann-Whitney U test or Student's t test, as appropriate. All tests were two-tailed and $\mathrm{p}$ values $<0.001 / 0.05$ were defined as significant. All statistical analyses were performed using SPSS (version 22.0 for Macintosh, IBM, Switzerland). The longitudinal change in the VIP level in paired samples ( $n=30$ and $n=24$; stable and exacerbated COPD) was analyzed by a non-parametric, paired test (Wilcoxon test). The MedCalc software (version 15.2, Belgium) was used for calculating sensitivity, specificity, negative likelihood ratio and positive likelihood ratio. The diagnostic accuracy of the serum VIP level for AECOPD was evaluated using receiver operating characteristic (ROC) analysis and area under the curve (AUC).

\section{Propensity Score Matching}

In order to compare study groups the data were adjusted for additional covariates by propensity score adjustment. Adjusted variables included all lung function as well as clinical and demographic characteristics as depicted in table 1.

The difference in serum VIP between the study groups (stable group, mild to moderate AE-COPD group and severe COPD group) was calculated using a regression model with the propensity score as an additional covariate [33].

\section{Results}

\section{Patient Characteristics}

The study design according to the Strengthening the Reporting of Observational Studies in Epidemiology (STROBE) guidelines and patient disposition is summa- 
Table 1. Characteristics of 241 patients included in the predefined VIP nested cohort at baseline (stable state)

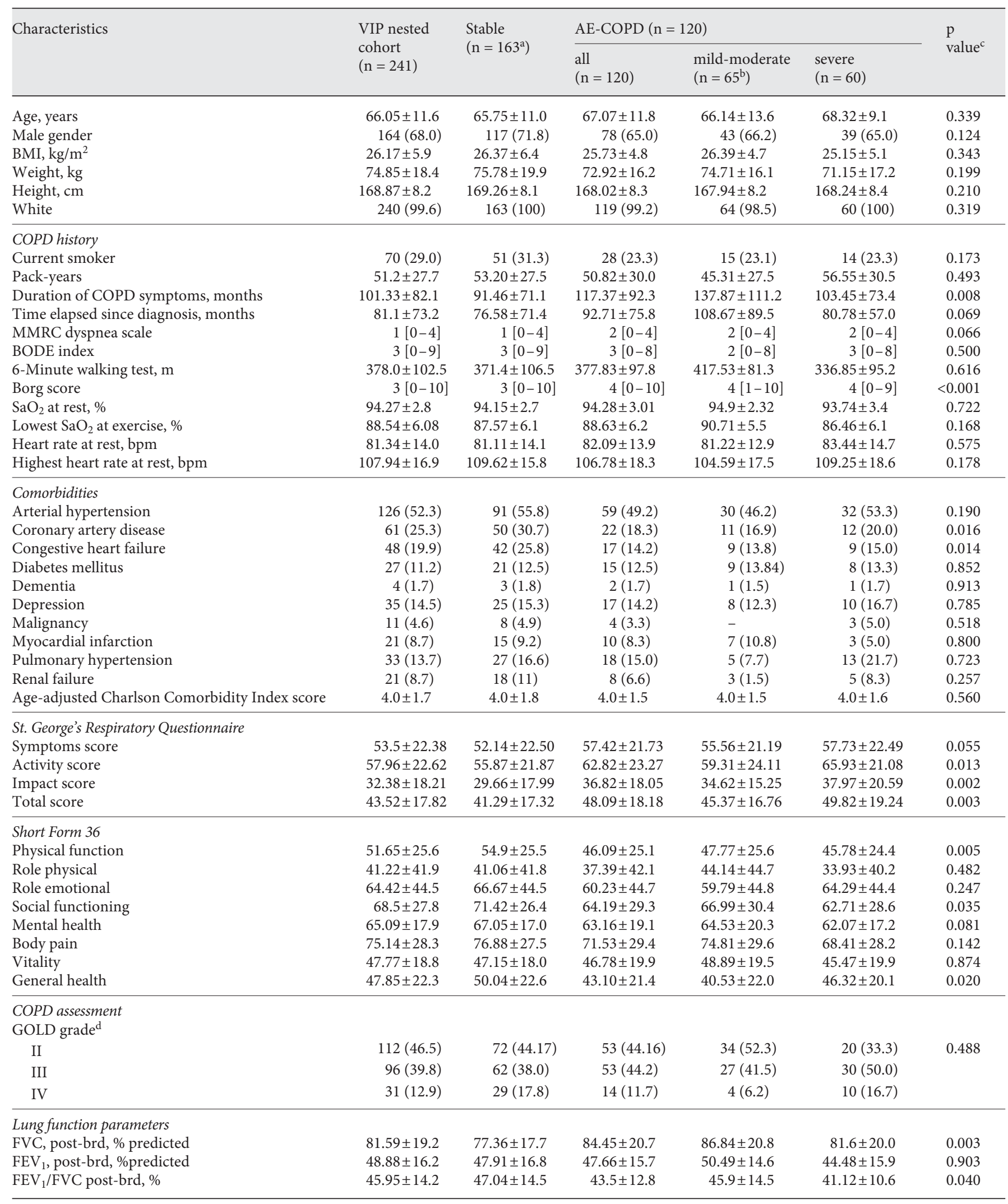

(For footnote see next page.) 
rized in figure 1. In total, 241 patients with GOLD grade II-IV were included in the predefined VIP nested cohort. Out of the 241, serum VIP levels were analyzed in 163 patients at stable state and in 120 patients with AE-COPD.

Table 1 depicts the demographic characteristics of stable patients in whom VIP level were assessed at both stable state and at exacerbation. The comparison of stable COPD versus AE-COPD showed similar demographics at baseline.

At baseline, the Borg score was significantly higher in patients developing AE-COPD $(\mathrm{p}<0.001)$. In contrast, the forced vital capacity (FVC post-bronchodilator percentage predicted) was significantly lower in stable COPD versus AE-COPD patients $(\mathrm{p}=0.003)$. Additionally, significant differences were found at baseline between patients who remained stable and those who had exacerbation during follow-up, for the activity score $(\mathrm{p}=0.013)$, the impact score $(\mathrm{p}=0.002)$, the total score $(\mathrm{p}=0.003)$ and physical function $(\mathrm{p}=0.005)$.

\section{Serum VIP Level in Stable and AE-COPD Patients}

Serum VIP levels were significantly higher in AECOPD patients (median $130.25 \mathrm{pg} / \mathrm{ml}, 95 \%$ CI 112.19 151.83 ) as compared to patients with stable COPD (me- dian $40.07 \mathrm{pg} / \mathrm{ml}$, 95\% CI 37.13-43.96, $\mathrm{p}<0.001)$. Importantly, the association of increased serum VIP with AE-COPD remained significant after propensity score matching $(\mathrm{p}<0.001)$. Serum VIP levels were similar in mild to moderate and severe AE-COPD $(\mathrm{p}=0.805)$ (fig. 2). Circulating serum VIP levels did not differ among Anthonisen's exacerbation types (type $1, \mathrm{n}=55$; type 2, $\mathrm{n}=25$; type $3, \mathrm{n}=35 ; \mathrm{p}=0.740$ ).

The longitudinal change in circulating VIP levels at stable state and at exacerbation for 30 patients is depicted in figure $3 \mathrm{a}$ and indicates a significant increase at exacerbation ( $\mathrm{p}<0.001)$. Out of these 30 patients, 6 had very high serum VIP at exacerbation. Upon exclusion of these extreme values, serum VIP level still remained significantly higher at exacerbation than at stable state $(\mathrm{p}<$ 0.001) (fig. 3b).

\section{Association of Serum VIP Level and Clinical Characteristics at Stable State}

At stable state, there was no significant difference of serum VIP comparing patients with comorbidities to those without history of myocardial infarction $(\mathrm{p}=0.936)$, arterial hypertension $(\mathrm{p}=0.731)$, coronary artery disease $(\mathrm{p}=0.831)$, diabetes mellitus $(\mathrm{p}=0.438)$, malignant solid
Fig. 1. STROBE flow chart of the patient cohort selection criteria. ${ }^{*} 42$ COPD patients were at stable state and had acute exacerbation. $* * 5$ patients had both mild to moderate and severe AE-COPD.

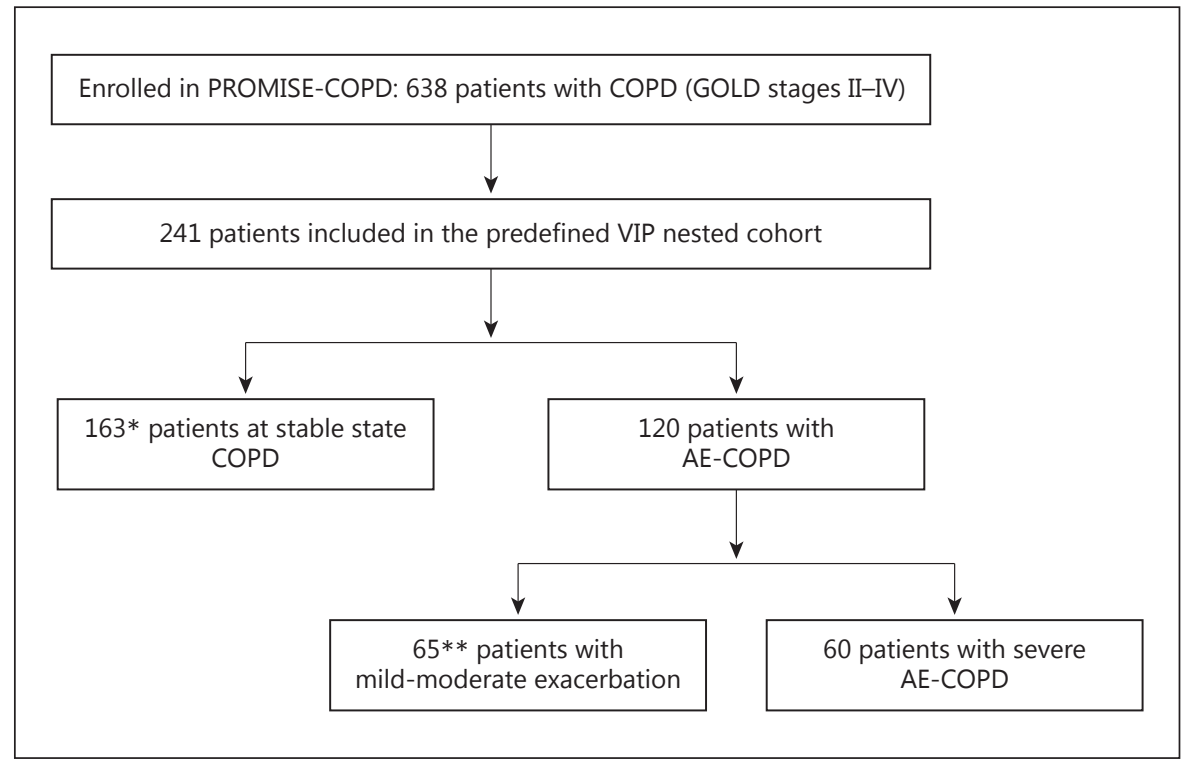

(Footnote to table 1.)

Continuous data are shown as mean $\pm \mathrm{SD}$ or median [interquartile range] and categorical variables as $\mathrm{n}(\%)$. BODE $=$ Body mass index, airflow obstruction, dyspnea and exercise capacity; bpm = beats/min; brd = bronchodilator; $\mathrm{SaO}_{2}=$ peripheral oxygen saturation. ${ }^{\mathrm{a}} 42 \mathrm{COPD}$ patients were at stable state and had acute exacerbation. ${ }^{\mathrm{b}} 5$ patients had both mild to moderate and severe AE-COPD. ${ }^{\mathrm{c}}$ Stable COPD versus AE-COPD (all). ${ }^{\mathrm{d}}$ GOLD grades are based on FEV $1 \%$ predicted: II $=\geq 50 \%$ and $<80 \%$; III $=\geq 30 \%$ and $<50 \%$; IV $=<30 \%$. There were no patients with GOLD grade I COPD due to the study inclusion criteria.

VIP for Diagnosing Exacerbation in COPD 


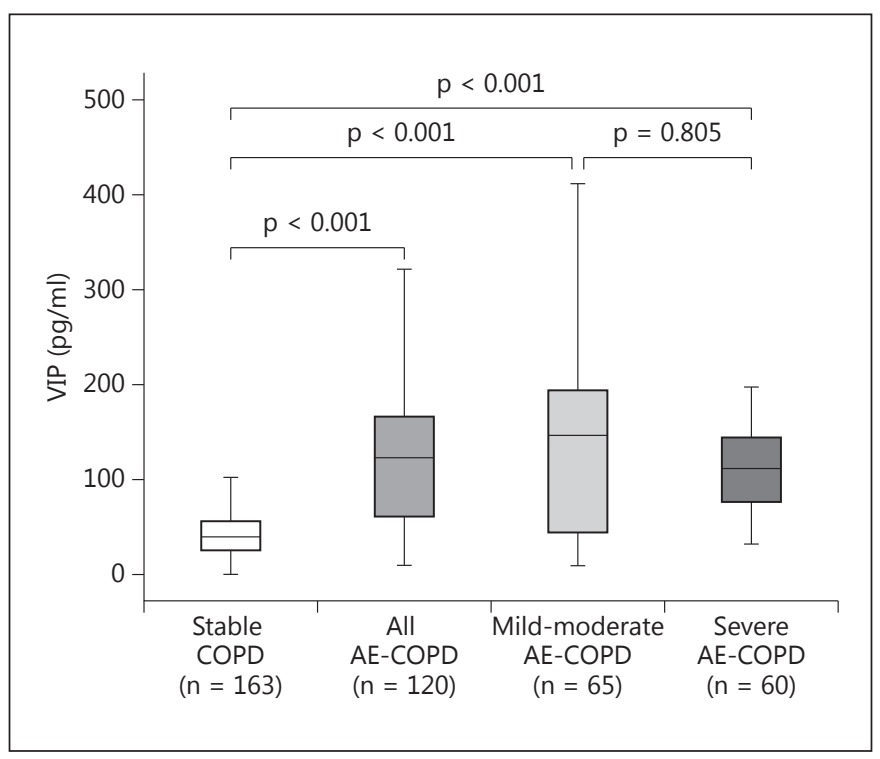

Fig. 2. Serum VIP in patients with stable COPD versus AE-COPD (data are expressed in box plots, vertical lines represent the 5th and the 95th percentiles). $\mathrm{p}$ values were calculated by Mann-Whitney $\mathrm{U}$ test.

tumor $(\mathrm{p}=0.899)$, PAH $(\mathrm{p}=0.361)$ and depression $(\mathrm{p}=$ $0.172)$. Conversely, VIP levels were significantly higher in patients with congestive heart failure $(p=0.035)$ and renal diseases $(\mathrm{p}=0.036)$ as compared to those without these comorbidities. There was no association between the serum VIP and post-bronchodilator FEV1\% predicted $(\mathrm{p}=$ $0.250)$. Serum VIP levels did not correlate with blood oxygen saturation at rest $(\mathrm{p}=0.722)$ or at exercise $(\mathrm{p}=0.168)$.

\section{Association of Serum VIP Level and Clinical}

Characteristics at Exacerbation

The clinical characteristics of patients at exacerbation are depicted in table 2. Cultures from sputum yielded pathogenic bacteria in 15 patients (12.5\%). Streptococcus pneumoniae accounted for 3.3\%, Klebsiella pneumoniae for $1.7 \%$, Chlamydia pneumoniae for 1.6\%, Haemophilus influenzae for $2.5 \%$ and Staphylococcus aureus for $1.7 \%$. Serum VIP did not correlate significantly with oxygen saturation at rest at exacerbation $(\mathrm{p}=0.322)$. Serum VIP levels showed no correlation to C-reactive protein ( $\mathrm{p}=$ 0.451). At exacerbation, we observed no association of serum VIP with relevant comorbidities ( $\mathrm{p}=$ not significant for all). However, AE-COPD patients with coronary artery disease had a significant increase in serum VIP $(\mathrm{p}=0.020)$. There was no association between circulating VIP levels and the duration of exacerbation $(p=0.260)$,
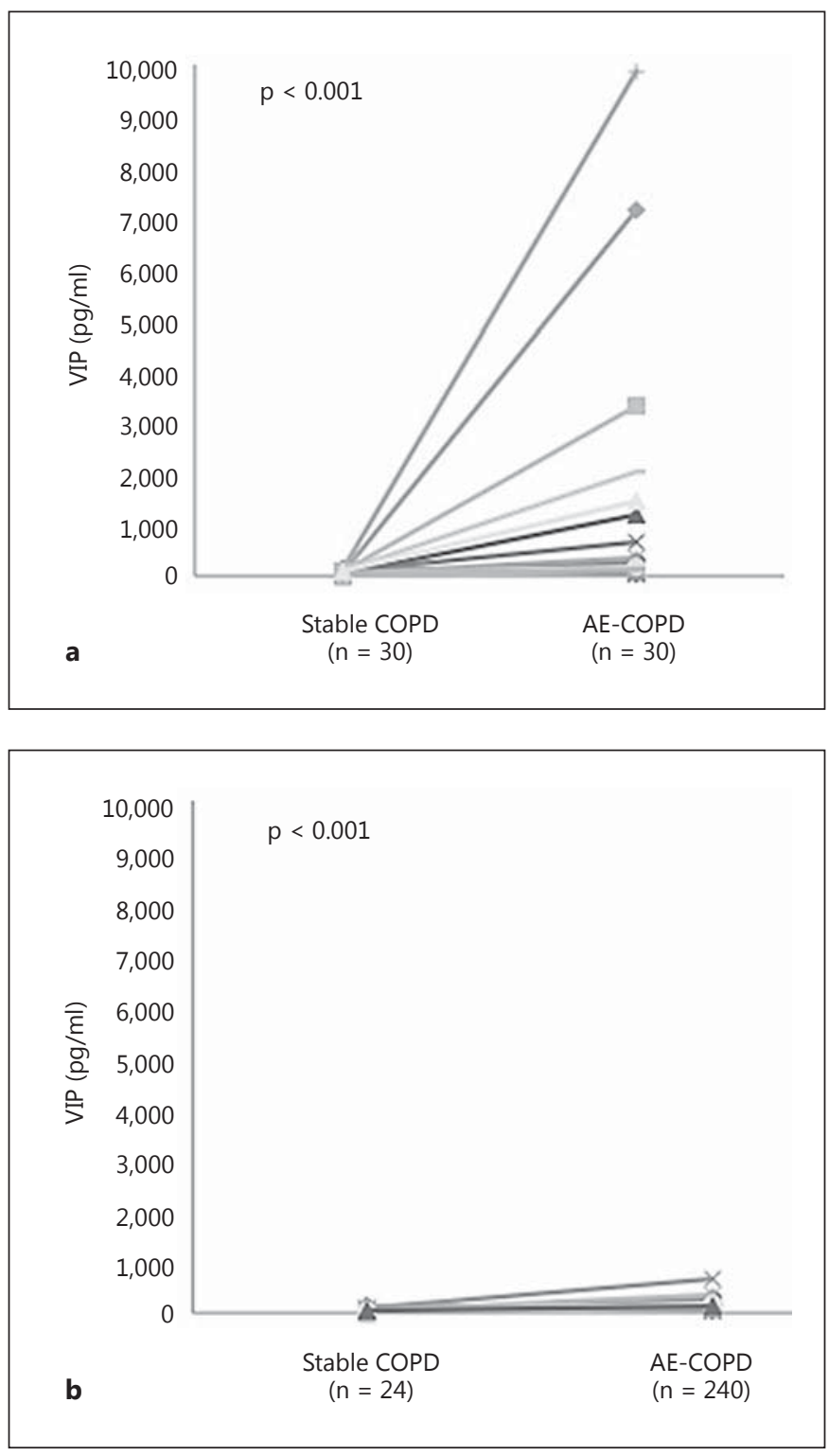

Fig. 3. a Comparison of serum VIP levels in paired patients $(\mathrm{n}=$ 30) with stable COPD versus AE-COPD. $\mathbf{b}$ Comparison of serum VIP levels in paired patients with stable COPD versus AE-COPD when extreme VIP values were excluded $(n=24)$. p value was calculated by Wilcoxon test.

dyspnea at exacerbation as assessed by the MMRC scale $(\mathrm{p}=0.092)$ or the presence of fever $(\mathrm{n}=20, \mathrm{p}=0.177)$. We found no significant association of VIP to leucocyte count $(\mathrm{p}=0.713)$ and FEV1\% predicted $(\mathrm{p}=0.805)$. VIP was neither associated to $\mathrm{PaO}_{2}(\mathrm{p}=0.286)$ nor $\mathrm{PaCO}_{2}$ $(\mathrm{p}=0.596)$. VIP levels were similar in those treated with and without oral steroids $(\mathrm{n}=83, \mathrm{p}=0.530)$ and antibiotics $(\mathrm{n}=74, \mathrm{p}=0.377)$. 
Table 2. Clinical characteristics of 120 patients at AE-COPD

Characteristics

Symptoms of exacerbation

Increased dyspnea

$111(92.5)$

Increased sputum volume

$74(61.6)$

Increased sputum purulence

$67(55.8)$

Sputum volume

No sputum

$21(17.5)$

Large amount ( $>1$ soup spoon)

$14(11.6)$

Moderate amount (1 soup spoon)

$43(35.8)$

Small amount (1 tea spoon)

$41(34.1)$

Sputum color

No sputum

$25(21.0)$

Purulent-green

$14(11.7)$

Purulent-yellow

$43(35.8)$

Transparent

$7(5.8)$

White

$30(25.0)$

$5[0-30]$

Duration of symptoms prior to visit

$86(71.6)$

\section{Sputum microbiology}

Sputum collected

$49(40.8)$

Good sputum quality

$41(34.1)$

Culture performed

$42(35.0)$

Potentially pathogenic microorganisms

$15(12.5)$

Treatment of exacerbation

Combination of inhaled beta2-agonists and anticholinergics

$40(33.3)$

Inhaled steroids

Oral, intramuscular or intravenous glucocorticosteroids

$30(25.0)$

Oral or intravenous antibiotics

$82(68.3)$

Oral or intravenous methylxanthines

$73(60.8)$

Oxygen

$12(10.0)$

$39(32.5)$

New prescription or increased dosage of diuretic therapy

$6(5.0)$

Severity of exacerbation

Patients requiring hospitalization

$15(12.5)$

Length of hospital stay, days

$10[1-28]$

Noninvasive mechanical ventilation

$3(2.5)$

Invasive mechanical ventilation

$1(0.8)$

Indications for hospital admission for COPD exacerbation

Marked increase in intensity of symptoms, such as sudden development of resting dyspnea

$34(28.3)$

$37(30.8)$

$9(7.5)$

$16(13.3)$

$20(16.6)$

$20(16.6)$

$1(0.83)$

$3(2.5)$

$21(17.5)$

$10(8.3)$

Insufficient home support

Indication for potential ICU admission of patients hospitalized with exacerbation of COPD

Severe dyspnea responding inadequately to initial emergency therapy

$2(1.6)$

Changes in mental status (confusion, lethargy, coma)

$3(2.5)$

Persistent or worsening hypoxemia $\left(\mathrm{PaO}_{2} 8.0 \mathrm{kPa}, 60 \mathrm{~mm} \mathrm{Hg}\right)$, and/or severe/worsening respiratory

$2(1.6)$

acidosis ( $\mathrm{pH}<7.25)$ despite supplemental oxygen and noninvasive ventilation

Hemodynamic instability - need for vasopressors

$1(0.83)$

Continuous data are shown as median [interquartile range] and categorical variables as n (\%). 


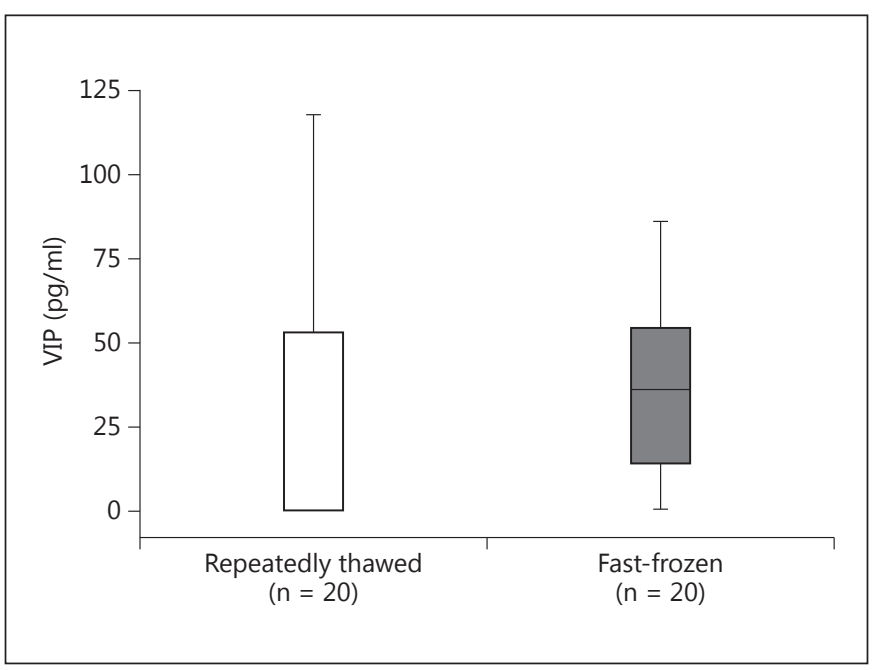

Fig. 4. Comparison of serum VIP levels in fast-frozen versus routinely processed serum samples $(n=20)$. Bars represent mean \pm SEM and $\mathrm{p}$ value was calculated by Wilcoxon test.

\section{Effect of Serum Processing on VIP Level}

Comparing serum VIP levels in fast-frozen serum samples directly and after repeated thawing from identical stable state COPD patients $(n=20)$, we observed that only fast-frozen serum contained measurable amounts of VIP, while repeated thawing $(1 \times)$ degraded VIP to undetectable levels (fig. 4).

\section{Diagnostic Performance of Serum VIP}

Using the AUC and 95\% CI of ROC analysis, increased serum VIP levels in AE-COPD proved to have a robust performance (AUC $0.849,95 \%$ CI $0.779-0.899$ ) to diagnose exacerbation (fig. 5a). According to the Youden index, the optimal cutoff value for serum VIP in AE-COPD was $56.6 \mathrm{pg} / \mathrm{ml}$. The probability of exacerbation was very low when serum VIP was $\leq 35 \mathrm{pg} / \mathrm{ml}$ (sensitivity $>90 \%$ ) and very high when serum VIP was $\geq 88 \mathrm{pg} / \mathrm{ml}$ (specificity $>90 \%$ ). We did not find a difference in the diagnostic performance in Anthonisen type 1, type 2 and type 3 patients.

Diagnostic performance of serum VIP improved (AUC 0.908, 95\% CI 0.838-0.978; AUC 0.910, 95\% CI $0.830-0.989)$ in patients having paired stable and exacerbation VIP levels $(n=30)$ (fig. 5b) and also when extreme VIP values were excluded $(\mathrm{n}=24)$ (fig. $5 \mathrm{c})$.

Upon dichotomizing by lung function, the performance of serum VIP tended to be better in GOLD grade II (sensitivity $=84.6 \%$, specificity $=76.0 \%$, negative likeli- hood ratio $=0.2$, positive likelihood ratio $=3.53$ ) than in GOLD grade III and IV (sensitivity $=76.1 \%$, specificity $=$ $75.8 \%$, negative likelihood ratio $=0.26$, positive likelihood ratio $=3.15$ ).

\section{Discussion}

We report that serum VIP is significantly higher at exacerbation as compared to stable state COPD, suggesting its diagnostic potential to identify COPD patients at exacerbation.

AE-COPD is a serious cause of increased morbidity, mortality and disease-related expenditures [34]. A biomarker with the potential to diagnose AE-COPD would therefore be beneficial for COPD management. Several serum markers have been reported to be upregulated at AE-COPD, such as C-reactive protein [4], copeptin and procalcitonin [35], tumor necrosis factor- $\alpha$ and leptin [36], endothelin-1 [37], fibrinogen [38, 39], IL-6 [40], IL-8 [41], eosinophil cationic protein, myeloperoxidase [42] and soluble urokinase-type plasminogen activator receptor [43]. However, there has been no report on the relationship of serum VIP and AE-COPD. Therefore, to our knowledge, this is the first study analyzing the serum VIP levels in COPD patients at stable disease and acute exacerbation.

Experimental studies showed that VIP relaxes vascular and non-vascular smooth muscles through the activation of adenylate cyclase and cyclic adenosine- $3^{\prime}, 5^{\prime}$-monophosphate (cAMP) production [44], and due to this function as a vasodilator and bronchodilator, VIP was suggested as a therapeutic target as well as a biomarker for COPD, asthma and PAH [27]. In this study we did not observe increased VIP serum levels in COPD patients with PAH and did not find a correlation of VIP serum levels with low oxygen saturation as suggested by animal studies and in vitro models [45-47]. It is difficult to explain this discrepancy between studies in animal and human beings, as it may not necessarily be reproducible in COPD patients. In murine models, lung remodeling and airway hyperreactivity increased when VIP levels were low, suggesting a therapeutic effect of exogenous VIP [26, 48]. In human epithelial cell lines VIP protected against hypoxia-induced tissue damage and increased experimental wound repair through cAMP-dependent regulatory signaling $[24,25]$. Regarding exacerbation caused by viral infection, VIP was protective in mice against cytomegalovirus-induced lung damage [19]. In contrast to these animal models, data obtained from human samples 

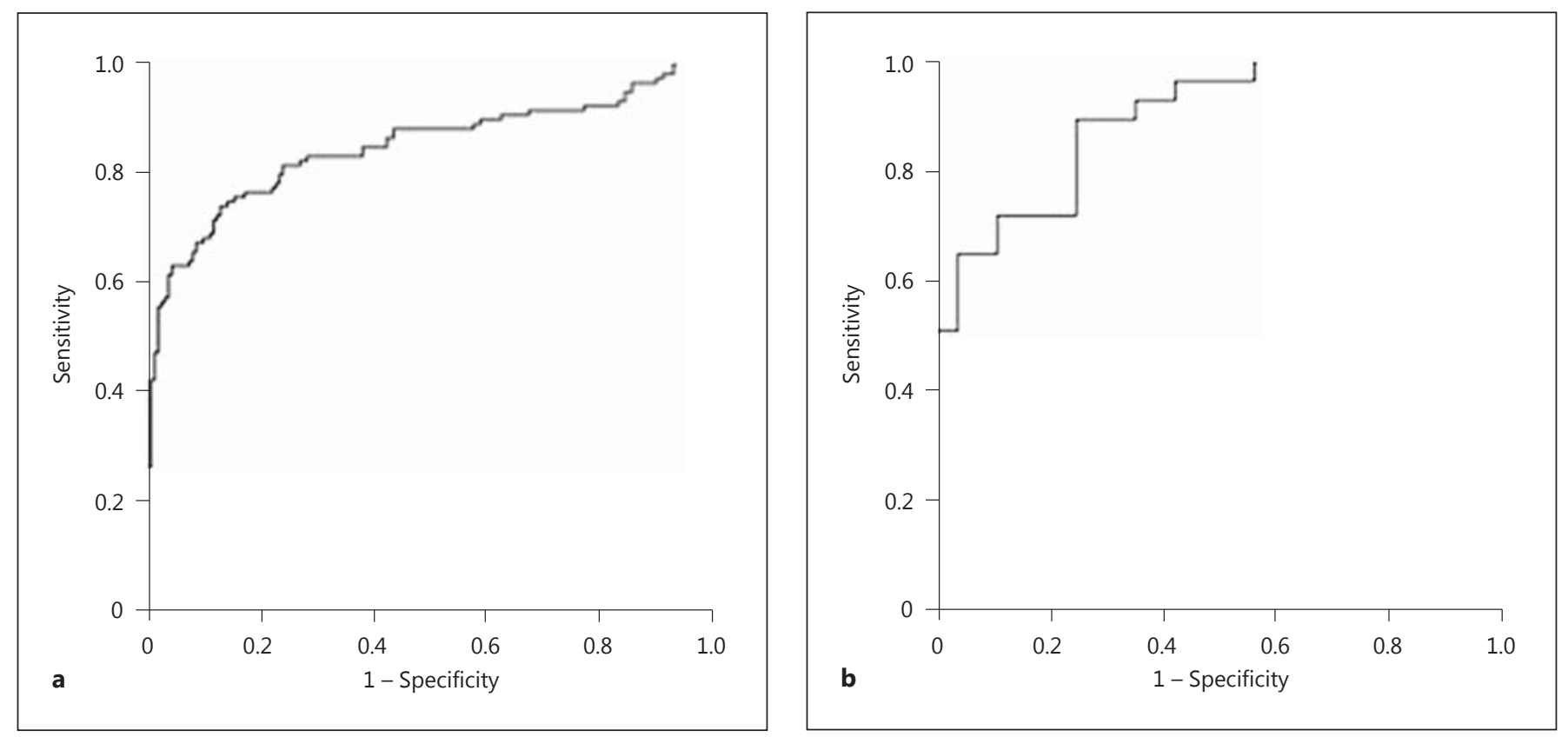

Fig. 5. a ROC curve of VIP ( $\mathrm{n}=283)$. AUC and 95\% CI: 0.849 $(0.799-0.899)$. b ROC curve of VIP in paired samples $(n=30)$. AUC and 95\% CI: 0.908 (0.838-0.978). c ROC curve of VIP in paired samples after the exclusion of extreme VIP values $(n=24)$. AUC and 95\% CI: 0.910 (0.830-0.989).

indicated that serum VIP increases under similar pathologic conditions, suggesting that VIP is distinctly regulated and has different functions in humans. Therefore the translation of animal studies to human diseases might not be straightforward.

In this study, we observed a strong correlation of increased serum VIP with AE-COPD and therefore suggest serum VIP as a potential biomarker to diagnose exacerba-

tion of COPD. This finding was supported by the longitudinal observation that serum VIP was increased at AECOPD compared to stable state.

Relating increased serum VIP in acute exacerbation to the protein's known biological functions, it remains unclear whether this is the cause or the result of exacerbation. VIP mediates its functions through two G proteincoupled receptors, the VIP-pituitary adenylate cyclase ac- 
tivating peptide receptors, VPAC1 and VPAC2 [49]. In humans and murine models the increased expression of VPAC1 in the airways of chronic bronchitis smokers, in the alveolar macrophages of COPD patients and in allergic asthma was reported [50-52]. This increased expression of VIP receptors may indicate that the ligand is missing, that the ligand is not active or that the signaling of the receptors is not correctly mediated. Unfortunately, up to now none of the previous studies has determined circulating VIP levels in these patients and examined their association to clinical characteristics, thus the role of VIP in COPD remains unclear.

Furthermore, our results confirm the short half-life of VIP $[53,54]$, as only the fast-frozen serum samples contained measurable amounts of VIP, while all other serum samples (repeatedly thawed, $1 \times$ ) had non-detectable or very low amounts of VIP, thus only fast-processed or freshly drawn blood samples can be used if VIP is considered as an indicator of COPD patients at exacerbation $[27,53-55]$.

Our study has few limitations. It was performed in a single center in Switzerland and included a relatively small number of patients with paired samples at exacerbation and at stable state. However, the diagnostic performance of VIP in the whole study population was robust and improved considerably when the analysis was restricted to the cohort with paired samples. A further limitation is the fact that, currently, there is no gold standard to diagnose exacerbation of COPD. Accordingly, the diagnostic performance of VIP was compared to the widely accepted clinical definition of exacerbation. It is unclear whether the diagnostic performance of VIP would be maintained in a population presenting with clinical symptoms caused by other entities, such as congestive heart failure, pulmonary embolism or pneumonia. Thus, further studies including patients with conditions mim- icking AE-COPD and a cost-effectiveness study comparing VIP (EUR 25) to other costly examinations potentially required to exclude AE-COPD (for instance, D-dimer EUR 32, brain natriuretic peptide EUR 70, chest X-ray EUR 120, chest CT EUR 250 and echocardiography EUR 350) would be of interest. Study strengths include the complete characterization of patients and disease characteristics at stable state and exacerbation and the dedicated sample handling for this particular biomarker determination. The study also benefits from the distinct diagnostic performance of the biomarker and the clinical potential associated with the presented findings.

\section{Conclusions}

We present data strongly suggesting that increased serum VIP in COPD patients indicates acute exacerbation. Therefore we suggest that serum VIP levels $\geq 88 \mathrm{pg} / \mathrm{ml}$ be used as an indicator of exacerbation in COPD patients.

\section{Acknowledgement}

The authors thank Anja Meyer, RN (Clinic of Pulmonary Medicine and Respiratory Cell Research, University Hospital Basel, Basel, Switzerland), for help in data collection, and Mr. Andy Schötzau, Dipl Math (www.eudox.ch), for statistical advice.

\section{Financial Disclosure and Conflicts of Interest}

Prof. Daiana Stolz was supported by the Swiss National Foundation (PP00-P3_128412/1). All authors report that no potential conflicts of interest exist with any companies/organizations whose products or services may be discussed in this article. The sponsors of this investigator-initiated project had no role in the design of the study, the collection and analysis of the data or the preparation of the manuscript.

\section{References}

1 Vestbo J, Hurd SS, Agusti AG, Jones PW, Vogelmeier C, Anzueto A, Barnes PJ, Fabbri LM, Martinez FJ, Nishimura M, Stockley RA, Sin DD, Rodriguez-Roisin R: Global strategy for the diagnosis, management, and prevention of chronic obstructive pulmonary disease: GOLD executive summary. Am J Respir Crit Care Med 2013;187:347-365.

-2 Murray CJ, Lopez AD: Alternative projections of mortality and disability by cause 1990-2020: Global Burden of Disease Study. Lancet 1997;349:1498-1504.
3 World Health Organization: Chronic obstructive pulmonary disease (COPD). Fact sheet $\mathrm{N}^{\circ} 315$. http://www.who.int/mediacentre/factsheets/fs315/en/ (accessed January 2015).

4 Hurst JR, Donaldson GC, Perera WR, Wilkinson TM, Bilello JA, Hagan GW, Vessey RS, Wedzicha JA: Use of plasma biomarkers at exacerbation of chronic obstructive pulmonary disease. Am J Respir Crit Care Med 2006;174: 867-874.

\footnotetext{
5 Criner GJ, Bourbeau J, Diekemper RL, Ouellette DR, Goodridge D, Hernandez P, Curren K, Balter MS, Bhutani M, Camp PG, Celli BR, Dechman G, Dransfield MT, Fiel SB, Foreman MG, Hanania NA, Ireland BK, Marchetti N, Marciniuk DD, Mularski RA, Ornelas J, Road JD, Stickland MK: Executive summary: prevention of acute exacerbation of COPD: American College of Chest Physicians and Canadian Thoracic Society Guideline. Chest 2015;147:883-893.
} 
6 Mackay AJ, Hurst JR: COPD exacerbations: causes, prevention, and treatment. Immunol Allergy Clin North Am 2013;33:95-115.

7 Prieto-Centurion V, Markos MA, Ramey NI, Gussin HA, Nyenhuis SM, Joo MJ, Prasad B, Bracken N, Didomenico R, Godwin PO, Jaffe HA, Kalhan R, Pickard AS, Pittendrigh BR, Schatz B, Sullivan JL, Thomashow BM, Williams MV, Krishnan JA: Interventions to reduce rehospitalizations after chronic obstructive pulmonary disease exacerbations. A systematic review. Ann Am Thorac Soc 2014;11: 417-424.

-8 Blasi F, Cesana G, Conti S, Chiodini V, Aliberti S, Fornari C, Mantovani LG: The clinical and economic impact of exacerbations of chronic obstructive pulmonary disease: a cohort of hospitalized patients. PLoS One 2014; 9:e101228.

\9 Decramer M, Janssens W, Miravitlles M: Chronic obstructive pulmonary disease. Lancet 2012;379:1341-1351.

10 Wouters EF: The burden of COPD in The Netherlands: Results from the Confronting COPD survey. Respir Med 2003;97(suppl C): S51-S59.

11 Rodriguez-Roisin R: Toward a consensus definition for COPD exacerbations. Chest 2000; 117(5 suppl 2):398S-401S.

12 Dahl M, Nordestgaard BG: Markers of early disease and prognosis in COPD. Int J Chron Obstruct Pulmon Dis 2009;4:157-167.

$\checkmark 13$ Koutsokera A, Kostikas K, Nicod LP, Fitting JW: Pulmonary biomarkers in COPD exacerbations: a systematic review. Respir Res 2013; 14:111.

14 Koutsokera A, Stolz D, Loukides S, Kostikas $\mathrm{K}$ : Systemic biomarkers in exacerbations of COPD: the evolving clinical challenge. Chest 2012;141:396-405.

15 Said SI, Mutt V, Yoshida T, Hara N: Vasoactive polypeptides from normal lung. Chest 1975;67(2 suppl):44S.

16 Spina D: Current and novel bronchodilators in respiratory disease. Curr Opin Pulm Med 2014;20:73-86.

17 Smalley SG, Barrow PA, Foster N: Immunomodulation of innate immune responses by vasoactive intestinal peptide (VIP): its therapeutic potential in inflammatory disease. Clin Exp Immunol 2009;157:225-234.

18 Onoue S, Aoki Y, Matsui T, Kojo Y, Misaka S, Mizumoto T, Yamada S: Formulation design and in vivo evaluation of dry powder inhalation system of new vasoactive intestinal peptide derivative ([R(15, 20, 21), L(17), $\mathrm{A}(24,25)$, des-N(28)]-VIP-GRR) in experimental asthma/COPD model rats. Int J Pharm 2011;410:54-60.

19 Li JM, Darlak KA, Southerland L, Hossain MS, Jaye DL, Josephson CD, Rosenthal H, Waller EK: VIPhyb, an antagonist of vasoactive intestinal peptide receptor, enhances cellular antiviral immunity in murine cytomegalovirus infected mice. PLoS One 2013;8: e63381.
20 Misaka S, Sato H, Aoki Y, Mizumoto T, Onoue S, Yamada S: Novel vasoactive intestinal peptide derivatives with improved stability protect rat alveolar L2 cells from cigarette smoke-induced cytotoxicity and apoptosis. Peptides 2011;32:401-407.

21 Onoue S, Ohmori Y, Endo K, Yamada S, Kimura R, Yajima T: Vasoactive intestinal peptide and pituitary adenylate cyclase-activating polypeptide attenuate the cigarette smoke extract-induced apoptotic death of rat alveolar L2 cells. Eur J Biochem 2004;271: 1757-1767.

22 Vatrella A, Montagnani S, Calabrese C, Parrella R, Pelaia G, Biscione GL, Corcione N, Marsico SA, Guerra G: Neuropeptide expression in the airways of COPD patients and smokers with normal lung function. J Biol Regul Homeost Agents 2010;24:425-432.

-23 Lacedonia D, Valerio G, Palladino GP, Carpagnano GE, Correale M, Di Biase M, Foschino Barbaro MP: Role of vasoactive intestinal peptide in chronic obstructive pulmonary disease with pulmonary hypertension. Rejuvenation Res 2014;17:33-39.

24 Guan CX, Cui YR, Sun GY, Yu F, Tang CY, Li YC, Liu HJ, Fang X: Role of CREB in vasoactive intestinal peptide-mediated wound healing in human bronchial epithelial cells. Regul Pept 2009;153:64-69.

25 Ao X, Fang F, Xu F: Vasoactive intestinal peptide protects alveolar epithelial cells against hyperoxia via promoting the activation of STAT3. Regul Pept 2011;168:1-4.

26 Czovek D, Petak F, Donati Y, Belin X, Pache JC, Barazzone Argiroffo C, Habre W: Prevention of hyperoxia-induced bronchial hyperreactivity by sildenafil and vasoactive intestinal peptide: impact of preserved lung function and structure. Respir Res 2014;15:81.

27 Wu D, Lee D, Sung YK: Prospect of vasoactive intestinal peptide therapy for COPD/PAH and asthma: a review. Respir Res 2011;12:45.

28 Global Initiative for Chronic Obstructive Lung Disease (GOLD): Global strategy for the diagnosis, management and prevention of COPD. GOLD, 2015. http://www.goldcopd. org/guidelines-global-strategy-for-diagnosis-management.html (last updated January 2015).

29 Pepe MS, Feng Z, Janes H, Bossuyt PM, Potter JD: Pivotal evaluation of the accuracy of a biomarker used for classification or prediction: standards for study design. J Natl Cancer Inst 2008; 100:1432-1438.

-30 ATS Committee on Proficiency Standards for Clinical Pulmonary Function Laboratories: ATS statement: guidelines for the six-minute walk test. Am J Respir Crit Care Med 2002; 166:111-117.

31 Isenberg H: Clinical Microbiology Procedures Handbook. Washington, Blackwell, 1992.

32 Anthonisen NR, Manfreda J, Warren CP, Hershfield ES, Harding GK, Nelson NA: Antibiotic therapy in exacerbations of chronic obstructive pulmonary disease. Ann Intern Med 1987;106:196-204.
3 Sjolander A: Propensity scores and M-structures. Stat Med 2009;28:1416-1420; author reply $1420-1423$.

34 Pauwels RA, Rabe KF: Burden and clinical features of chronic obstructive pulmonary disease (COPD). Lancet 2004;364:613-620.

- 35 Stolz D, Christ-Crain M, Morgenthaler NG, Leuppi J, Miedinger D, Bingisser R, Muller C, Struck J, Muller B, Tamm M: Copeptin, $\mathrm{C}$-reactive protein, and procalcitonin as prognostic biomarkers in acute exacerbation of COPD. Chest 2007;131:1058-1067.

- 36 Calikoglu M, Sahin G, Unlu A, Ozturk C, Tamer L, Ercan B, Kanik A, Atik U: Leptin and TNF-alpha levels in patients with chronic obstructive pulmonary disease and their relationship to nutritional parameters. Respiration 2004;71:45-50.

37 Roland M, Bhowmik A, Sapsford RJ, Seemungal TA, Jeffries DJ, Warner TD, Wedzicha JA: Sputum and plasma endothelin-1 levels in exacerbations of chronic obstructive pulmonary disease. Thorax 2001;56:30-35.

-38 Mannino DM, Tal-Singer R, Lomas DA, Vestbo J, Graham Barr R, Tetzlaff K, Lowings M, Rennard SI, Snyder J, Goldman M, Martin UJ, Merrill D, Martin AL, Simeone JC, Fahrbach K, Murphy B, Leidy N, Miller B: Plasma fibrinogen as a biomarker for mortality and hospitalized exacerbations in people with COPD. Chronic Obstr Pulm Dis (Miami) 2015;2:23-34.

39 Wedzicha JA, Seemungal TA, MacCallum PK, Paul EA, Donaldson GC, Bhowmik A, Jeffries DJ, Meade TW: Acute exacerbations of chronic obstructive pulmonary disease are accompanied by elevations of plasma fibrinogen and serum IL-6 levels. Thromb Haemost 2000;84:210-215.

40 Hurst JR, Perera WR, Wilkinson TM, Donaldson GC, Wedzicha JA: Systemic and upper and lower airway inflammation at exacerbation of chronic obstructive pulmonary disease. Am J Respir Crit Care Med 2006;173: 71-78.

41 Spruit MA, Gosselink R, Troosters T, Kasran A, Gayan-Ramirez G, Bogaerts P, Bouillon R, Decramer M: Muscle force during an acute exacerbation in hospitalised patients with COPD and its relationship with CXCL8 and IGF-I. Thorax 2003;58:752-756.

42 Fiorini G, Crespi S, Rinaldi M, Oberti E, Vigorelli R, Palmieri G: Serum ECP and MPO are increased during exacerbations of chronic bronchitis with airway obstruction. Biomed Pharmacother 2000;54:274-278.

43 Gumus A, Altintas N, Cinarka H, Kirbas A, Haziroglu M, Karatas M, Sahin U: Soluble urokinase-type plasminogen activator receptor is a novel biomarker predicting acute exacerbation in COPD. Int J Chron Obstruct Pulmon Dis 2015;10:357-365. 
44 Desbuguois B, Laudat MH, Laudat P: Vasoactive intestinal polypeptide and glucagon: stimulation of adenylate cyclase activity via distinct receptors in liver and fat cell membranes. Biochem Biophys Res Commun 1973; 53:1187-1194.

-45 Hamidi SA, Prabhakar S, Said SI: Enhancement of pulmonary vascular remodelling and inflammatory genes with VIP gene deletion. Eur Respir J 2008;31:135-139.

-46 Liu H, Yang X, Hou W: Correlation of c-fos protein expression with neuropeptide content in the lung of bronchial asthmatic rat. Int J Clin Exp Pathol 2014;7:8657-8665.

-47 Yin J, Wang L, Yin N, Tabuchi A, Kuppe H, Wolff G, Kuebler WM: Vasodilatory effect of the stable vasoactive intestinal peptide analog RO 25-1553 in murine and rat lungs. PLoS One 2013;8:e75861.
48 Leuchte HH, Prechtl C, Callegari J, Meis T, Haziraj S, Bevec D, Behr J: Augmentation of the effects of vasoactive intestinal peptide aerosol on pulmonary hypertension via coapplication of a neutral endopeptidase 24.11 inhibitor. Am J Physiol Lung Cell Mol Physiol 2015;308:L563-L568.

49 Laburthe M, Couvineau A: Molecular pharmacology and structure of VPAC receptors for VIP and PACAP. Regul Pept 2002;108: 165-173.

50 Burian B, Storka A, Marzluf BA, Yen YC, Lambers C, Robibaro B, Vonbank K, Mosgoeller W, Petkov V: Vasoactive intestinal peptide (VIP) receptor expression in monocyte-derived macrophages from COPD patients. Peptides 2010;31:603-608.

51 Lauenstein HD, Quarcoo D, Welte T, Braun A, Groneberg DA: Expression of VPAC1 in a murine model of allergic asthma. J Occup Med Toxicol 2013;8:28.
52 Miotto D, Boschetto P, Bononi I, Zeni E, Cavallesco G, Fabbri LM, Mapp CE: Vasoactive intestinal peptide receptors in the airways of smokers with chronic bronchitis. Eur Respir J 2004;24:958-963.

53 Dey RD, Shannon WA Jr, Said SI: Localization of VIP-immunoreactive nerves in airways and pulmonary vessels of dogs, cat, and human subjects. Cell Tissue Res 1981;220: 231-238.

54 Minkes RK, McMahon TJ, Higuera TR, Murphy WA, Coy DH, Kadowitz PJ: Analysis of systemic and pulmonary vascular responses to PACAP and VIP: role of adrenal catecholamines. Am J Physiol 1992;263(6 Pt2):H1659H1669.

55 Groneberg DA, Rabe KF, Fischer A: Novel concepts of neuropeptide-based drug therapy: vasoactive intestinal polypeptide and its receptors. Eur J Pharmacol 2006;533:182194 